\title{
An Electro-Mechanical Controller for Adjusting Piston Pump Stroke On-the-Go for Site-Specific Application of Crop Nutrients
}

\author{
Ali Mirzakhani Nafchi', Joe Mari Maja², Ahmad Khalilian1, Young Han', Nicholas Rogers1, \\ Jose 0. Payero' ${ }^{2}$, Michael W. Marshall2 ${ }^{2}$, Phillip B. Williams ${ }^{1}$, Jonathan Fox ${ }^{1}$ \\ ${ }^{1}$ Department of Agricultural Sciences, Clemson University, Clemson, SC, USA \\ ${ }^{2}$ Edisto Research and Education Center, Clemson University, Blackville, SC, USA \\ Email: anafchi@clemson.edu, jmaja@clemson.edu, *akhlln@clemson.edu, yhan@clemson.edu, ngroger@g.clemson.edu, \\ jpayero@clemson.edu,marsha3@clemson.edu,pbw@clemson.edu,jwfox@g.clemson.edu
}

How to cite this paper: Nafchi, A.M., Maja, J.M., Khalilian, A., Han, Y., Rogers, N., Payero, J.O., Marshall, M.W., Williams, P.B. and Fox, J. (2017) An Electro-Mechanical Controller for Adjusting Piston Pump Stroke On-the-Go for Site-Specific Application of Crop Nutrients. Agricultural Sciences, 8, 949-959.

https://doi.org/10.4236/as.2017.89069

Received: August 18, 2017

Accepted: September 8, 2017

Published: September 12, 2017

Copyright (c) 2017 by authors and Scientific Research Publishing Inc. This work is licensed under the Creative Commons Attribution International License (CC BY 4.0).

http://creativecommons.org/licenses/by/4.0/

\begin{abstract}
Nutrient application systems are designed to apply a relatively uniform amount of a fertilizer to agricultural fields. However, considerable variation in soil texture and other characteristics often occurs within and across production fields, which could have a major impact on fertilizer management strategies. Therefore, uniform application of a fertilizer over the entire field can be both costly and environmentally unsound. Due to their rugged and fool-proof design, crankshaft type piston pumps are widely used in agriculture. The on-the-go outlet flow of these pumps can only be varied by changing the drive shaft speed for each pump stroke setting. But only a limited range of flow rates can be achieved by changing the drive shaft speed. There is a need for an electronic controller, which can adjust the pump stroke on-the-go, for realtime, variable-rate application of crop nutrients. The Clemson "Electro-mechanical controller for adjusting pump stroke on-the-go" was designed to replace the current manual stroke adjustment system on positive displacement piston pumps. This affordable system can be retrofitted on most John Blue piston pumps for real-time adjustment of the pump stroke and can be controlled using pre-described position sequences (map-based) or real-time sensor commands (such as optical, pressure, and flow sensors) combined with fertilizer calculation algorithms. In addition, it can adjust pump stroke manually, using an eclectic dial from the tractor's cab.
\end{abstract}

\section{Keywords}

Electro-Mechanical Controller, Metering Piston Pumps, Nutrient Management, Precision Agriculture, Pump Stroke 


\section{Introduction}

Crop nutrient application systems are designed to apply a relatively uniform amount of a fertilizer to agricultural fields. However, considerable variation in soil texture, soil type, and other major factors often occurs within and across production fields, which affect crop production and could have a major impact on fertilizer management strategies. Therefore, uniform application of a fertilizer over the entire field can be both costly and environmentally unsound. On average, growers in the USA apply about $100 \mathrm{~kg} / \mathrm{ha} \mathrm{N}$ for cotton, $160 \mathrm{~kg} / \mathrm{ha}$ for corn, and $100 \mathrm{~kg} / \mathrm{ha}$ for wheat, for a total of 8.2 million metric tons just for these three crops. Sensor-based, variable-rate fertilizer application has a potential to reduce fertilizers application rates by half [1]. Even a $20 \%$ reduction in $\mathrm{N}$ use could save cotton, corn and wheat growers over $\$ 1.8$ billion annually.

Variable-rate positive displacement piston pumps are widely used for metering chemicals with high level of repetitive accuracy and are capable of pumping a wide range of chemicals. These pumps have ability to vary capacity manually or automatically as process conditions require. Variable-rate positive displacement pumps are typically more energy efficient because flow and pressure (horsepower) more closely matches load.

For axial positive displacement piston pumps, output flow can be varied by changing the swash plate angle. This angle usually is changed manually with an adjustable screw that can also be replaced by an electronic device. Several techniques have been used for controlling the swash plate angle, and thereby the outlet flow of these pumps automatically [2] [3] [4] [5] [6].

Crankshaft type variable-rate piston pumps (such as John Blue) are used widely in agriculture, due to their rugged design (CDS-John Blue Company, Huntsville, AL). Currently, there are over one million crankshaft-type positivedisplacement piston pumps in the USA, which are used by row-crop and hay farmers for applying crop inputs. The outlet flow of these pumps can be changed by adjusting pump stroke manually ("stop-and-go" system), using specific tools provided by the company. The manufacturers also offer an optional "on-the-go" system, but the outlet flow can only be varied by changing the drive shaft speed for each pump stroke setting. In a previous study [7], a ground driven John Blue pump was attached to a hydraulically-operated variable-speed motor, controlled by a Rawson Control system (Trimble Navigation Company, Ukiah, CA). In this study, the Rawson system controlled $\mathrm{N}$ rates by changing the shaft speed, based on a prescription map, for each pump stroke settings. They reported errors in application rates ranging from $-16 \%$ to $34 \%$, mainly due to the pump's limitations for applying the lowest and highest rates of fertilizer at a given stroke setting. In 2009, the CDS-John Blue Company introduced a variable rate hydraulic option, which can be coupled to any CDS-John Blue piston pump, and change pump's outlet flow (by changing shaft speed) on-the-go, from the tractor's cab. However, with these systems, only a limited range of flow rates can be achieved by changing the drive shaft speed [8]. This limited flow range is not sufficient for 
applying variable-rate crop inputs in fields with tremendous amount of variation in soil types, resulting in practice that is wasteful, costly, and environmentally questionable.

A variable stroke-length pump, with an internal pinion gear and counter-rotating nested eccentrics, was described by Jones [9]. With this system, drive gears are rotationally fixed to each of the eccentrics and geared to each other through an intermediate pinion gear. An actuator is geared to the pinion bracket that holds the pinion and can be actuated on-the-fly to alter the output oscillation stroke length and flow rate of the pump. This controller is an internal part of the pump and cannot be moved from one type of a piston pump to another. Therefore, the objective of this project was to develop a controller that could be retrofitted to growers' existing piston pumps, which could adjust the pump stroke on-the-go, for real-time, variable-rate application of crop nutrients.

\section{Methodology}

\subsection{Design Specifications}

The Clemson "Electro-mechanical controller for adjusting pump stroke on-the-go" was designed to replace the current manual stroke adjustment system on positive displacement piston pumps. The controller was designed according to several design specifications where the system should be: 1) easily retrofitted on most existing John Blue piston pumps for real-time adjustment of the pump stroke; 2) controlled using pre-described position sequences, and could communicate with GPS and any GIS software, such as "Farm Site Mate" (Farm Works Software LTD), for precise and map-based application of products; 3) able to receive real-time sensor-based commands, such as optical (GreenSeeker), pressure, or flowmeter sensors, calculate the required crop input rates (such as $\mathrm{N}$ ) using algorithms, and adjust the pump stroke accordingly; 4) able to adjust the pump stroke manually from the tractor's cab, using a pre-calibrated electric dial; and 5) a low cost option for farmers.

The controller consists of two main components: an electro-mechanical system and an electronic control system.

\subsection{Electro-Mechanical System}

The output of a variable stroke, positive displacement, crankshaft type piston pump (such as john Blue) can be adjusted manually by moving the "Setting Pointer" of the pump (Figure 1) to a pre-defined position on the "Setting Hub." The pointer and hub are connected to the inner and outer eccentrics of the piston pump; therefore, this movement will result in a change in the pump's stroke length. The Clemson pump stroke controller-consists of a pair of nested male and female spiral gears, in which one is connected to the Setting Pointer and the other is connected to the Setting Hub (Figure 1).

A linear movement of one spiral gear with respect to the other spiral gear results in the rotation of the pump's inner eccentric with respect to the outer 


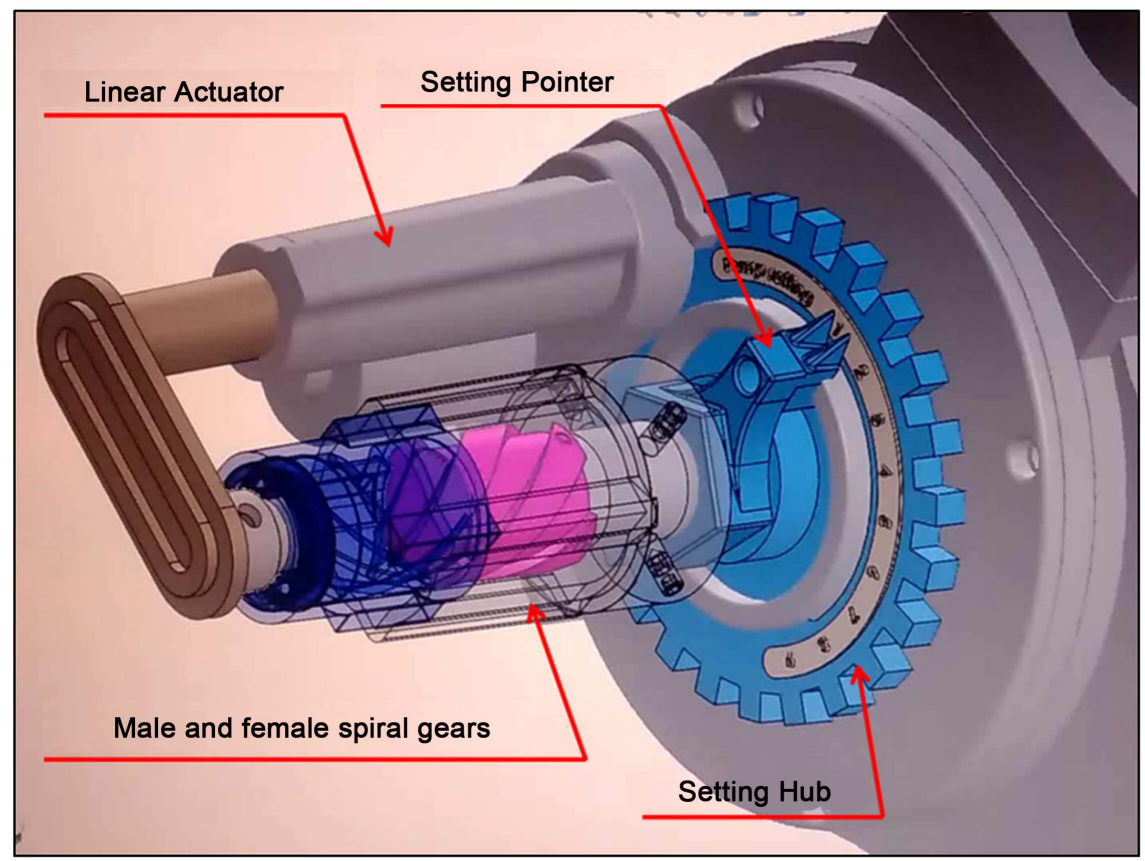

Figure 1. Schematic diagram of the spiral gears and the linear actuator, attached to a John Blue pump.

eccentric; therefore, changing the pump's stroke length and outlet flow. The movement of the spiral gears with respect to each other is controlled by a linear actuator. A 12VDC linear actuator (Concentric International, model: LACT2P), with a $5-\mathrm{cm}$ stroke and built-in potentiometer for position feedback, was used to control the movement of the spiral gears with respect to each other. The actuator's motor has a 20:1 reduction gearbox that gives the actuator a dynamic load rating of $50 \mathrm{~kg}$ and a maximum speed of $1.3 \mathrm{~cm} / \mathrm{s}$. Limit switches at each end make the actuator easy to control over its full range of motion, while integrated diodes allow it to reverse direction after reaching a limit point if the supplied voltage is reversed. The actuator was coupled to the female spiral gear through an actuator arm in a rotatable manner, using a bearing assembly, such that the female spiral gear can rotate relative to the actuator arm. The other end of the female spiral gear was attached to the outer eccentric of the pump. The female spiral gear produces a rotation of the male spiral gear, which was coupled to the pump's inner eccentric, thereby adjusting the pump-stroke length. The linear actuator was attached to the base plate on the pump. Figure 2(a) shows the Clemson electro-mechanical controller, installed on a John Blue piston pump. The proto-type controller system is installed on a commercially available $\mathrm{KBH}$ fertilizer applicator (Figure 2(b)).

\subsection{Electronic Control System}

The electronic control module consists of a high performance, low-power 8-bit microcontroller (Atmega644P, Atmel, San Jose, CA), which has 64 kilobytes of 


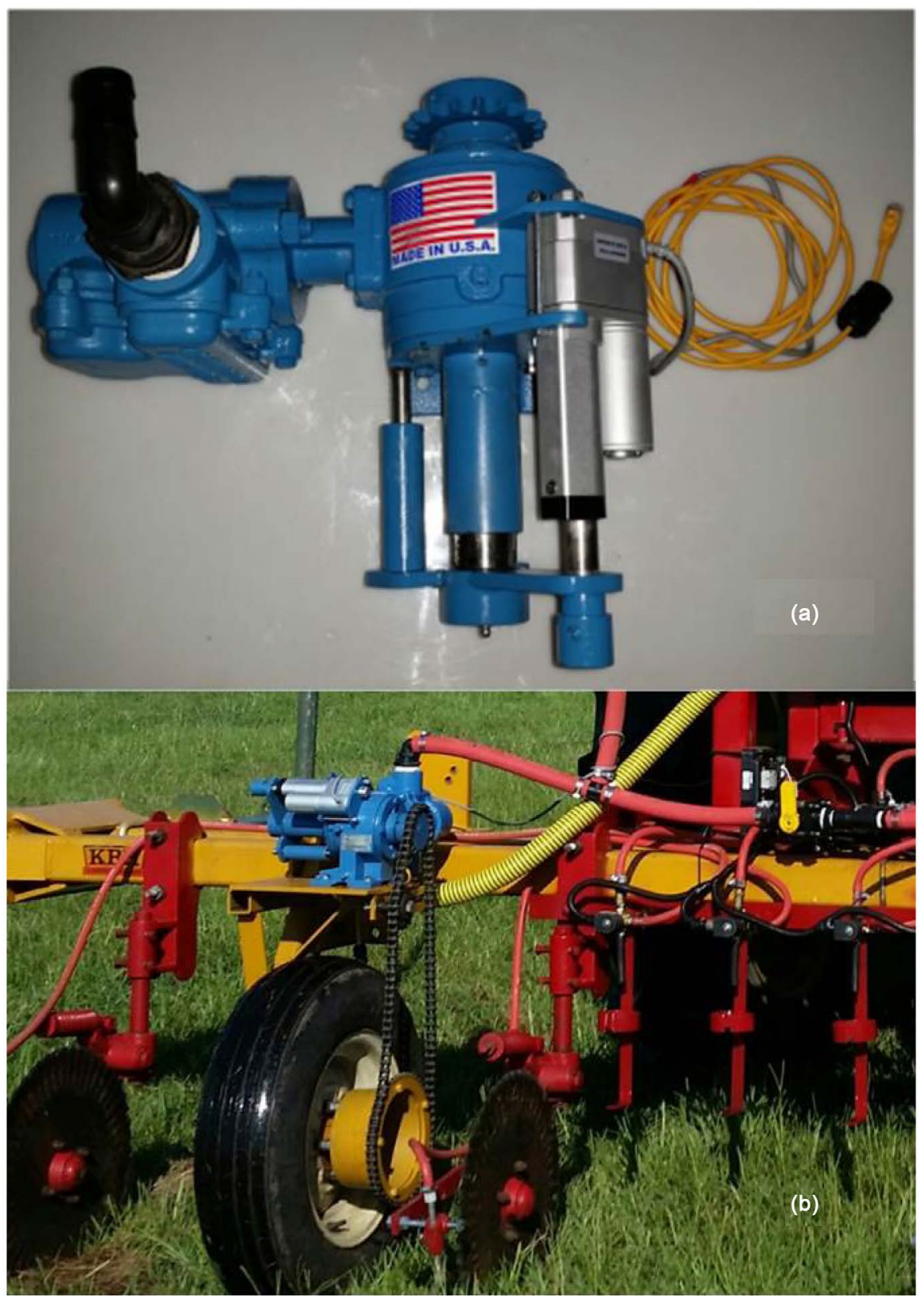

Figure 2. (a)The Clemson electro-mechanical controller, retrofitted to a John Blue piston pump (b), KBH nutrient applicator.

program memory, 2 kilobytes of EPROM, and 32 programmable I/O lines. The design of the electronic control module was based on the Clemson University's Intelligent Farm Controller (iFc) [10]. All components of the electronic control module (Figure 3) were developed at the Edisto REC Sensor and Automation Laboratory. Aside from controlling the linear actuator, the module has external interfaces to both an NDVI sensor (Trimble GreenSeeker, Sunnyvale, CA), through a RS232 and to a Personal Computer (PC) usinga Universal Serial Bus (USB) connection.

The controller is also equipped with a one-turn potentiometer input (Poti), 


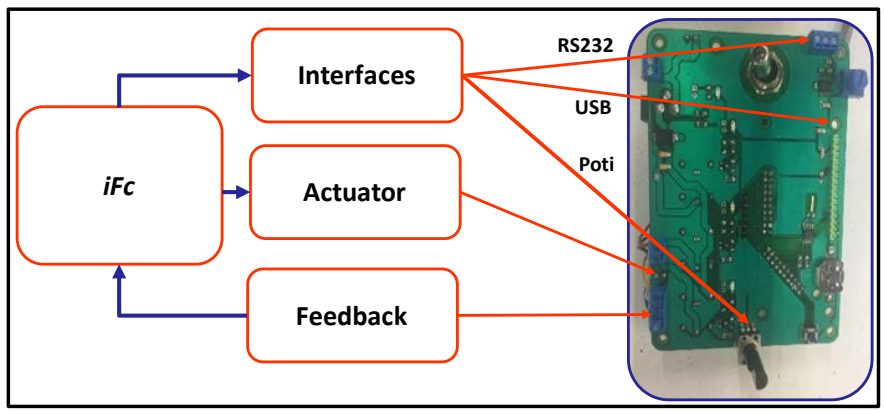

Figure 3. The electronic control module interconnectivity with different interfaces, actuator, and feedback.

which provides a manual control for the actuator. The NDVI sensor interface allows automatic adjustment of the linear actuator based on the NDVI sensor values, while the PC interface allows map-based control, using PC-based software.

The linear actuator (Figure 4(a)) has a built-in potentiometer, which provides a position feedback. The position feedback was connected to one of the Analog to Digital Converter (ADC) pins (10 bit) of the iFc, and was converted into percentage in terms of the full stroke of the actuator (swing) as:

$$
\text { swing }(\%)=\frac{A D C \text { value }}{1026} \times 100 \%
$$

The same equation was used to calculate the potentiometer input (Poti) for the manual control (Figure 4(b)). This will provide consistency in terms of different potentiometer maximum values as it was normalized based on the maximum ADC values of the microcontroller. The control box provides a simplified menu at startup for the user to choose:

- Manual-provides the user with an eclectic dial (potentiometer) located on the box, which can be used to manually control the displacement of the actuator from the tractor's cab (Figure 4(b)). This action will adjust pump stroke length and $\mathrm{N}$ rates manually.

- Sensor-provides an automatic displacement of the actuator based on an optical-sensor reading (such as NDVI values from a GreenSeeker optical sensor). It can also be controlled using inputs from an electronic pressure sensor or inputs from a flowmeter.

- PC-provides automatic displacement of the actuator based on the map-based program connected to the USB of the electronic control box. The $\mathrm{N}$ prescription maps can be uploaded on a rate controller such as Trimble, Raven or AgLeader monitors, as a well as an onboard computer (PC) inside the tractor's cab.

The "Manual" control does not drive the actuator directly based on the selected percentage of displacement (potentiometer), instead it will take the input percentage and will wait until the user presses "*” on the keypad before it will start changing the position. 


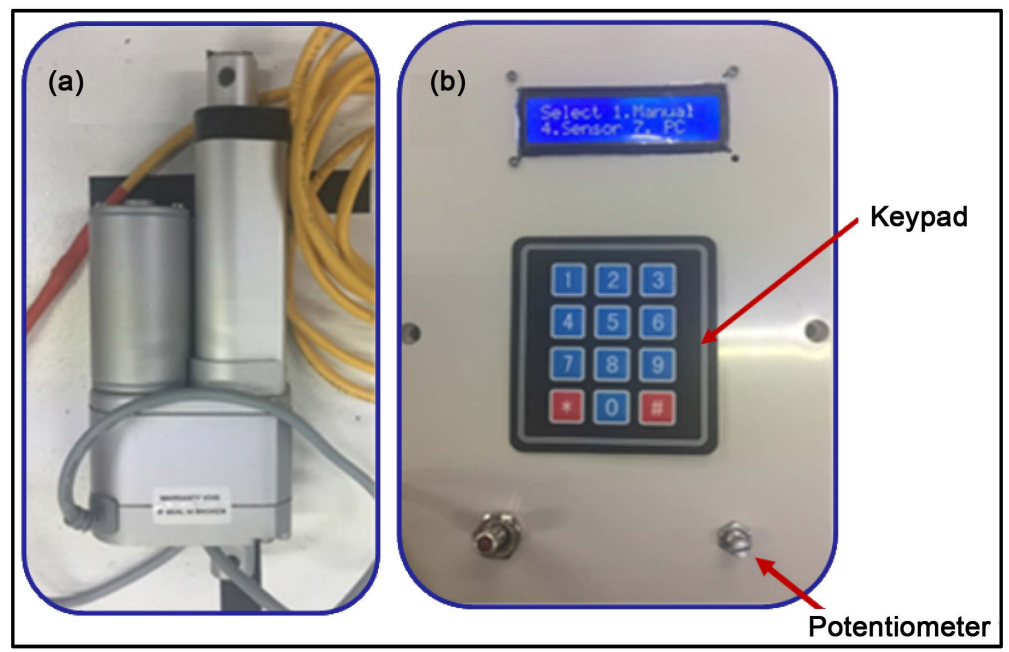

Figure 4. (a) Linear actuator and (b) electronic control box.

The "Sensor" control is used to control pump stroke and $\mathrm{N}$ rates based on an optical-sensor readings and $\mathrm{N}$ algorithms developed at Clemson University, for selected crops [1] [7] [8]. The $\mathrm{N}$ algorithms require information (such as planting date, NDVI from a N rich strip and from the field, and max expected yield) to calculate the appropriate amount of side dress $\mathrm{N}$ needed under given conditions (previous crop, soil texture, rainfall, etc.). The electronic control box has a Real Time Clock module, model DS3231M (Maxim Integrated, San Jose, CA), which provides an accurate date and time. This information is used for the algorithm to calculate the number of days from planting to sensing. After the user inputs all the required data for the algorithm, the electronic control module will then calculate the amount of actuator displacement based on the real-time sensor value generated by the GreenSeeker. The USB interface will also display any information passed by the sensor to the electronic control box.

The "PC" control provides a direct communication to the electronic control box through the USB interface. The command to change the displacement is "rt \%". Valid \% values range from 0 to 100 and are also displayed on the LCD screen whatever was received from the PC. The rate values from a N prescription map are converted to percent of the full stroke of the actuator.

The firmware for the controller was written in the embedded $\mathrm{C}$ language, to handle all communications (interfaces, actuator, and feedback), to convert NDVI values to $\mathrm{N}$ rates, and control the actuator. The change in actuator's stroke length would translate in a change in piston pump's stroke length and pump's outlet flow.

\subsection{Field Tests}

System performance tests were conducted under actual field conditions. The first test was conducted to determine the accuracy of the electric dial for changing the pump's stroke length compared to manually adjusted pump stroke (using special tools provided by the manufacturer). Tests were replicated four times for each 
pump settings. A simple device was developed to collect $\mathrm{N}$ samples during the field test. A 3-way solenoid valve was inserted at the discharge end of each chemical hose. In normal solenoid mode the system applied $\mathrm{N}$ to the row crop. By energizing the solenoid, $\mathrm{N}$ was directed into a collection bottle installed at each row of the applicator. Samples were collected for $30 \mathrm{~m}$ and the measured rates of $\mathrm{N}$ from manually and electronically controlled systems were compared.

In addition, the Clemson electro-mechanical controller was used to apply different rates of $\mathrm{N}$ under field condition. Six target rates $(3,45,67,90,120$, and $163 \mathrm{~kg} / \mathrm{ha}$ ) were selected for the controller's performance test. Each test was replicated four times. Again, $\mathrm{N}$ samples were collected for $30 \mathrm{~m}$ using the 3-way solenoid valve system. The target and actual measured $\mathrm{N}$ rates were compared to determine the accuracy of the system.

The statistical analysis was conducted using the SAS software (Version: 9.4; SAS Institute Inc., Cary, NC, USA). F-values from analysis of variance were considered significant at a probability level of 0.05 . When sources of variation were significant, means were separated by calculating a least significant difference (LSD).

\section{Results}

The system closely followed the design specifications described in the Methodology section. The results of field test showed an excellent correlation $\left(\mathrm{R}^{2}=\right.$ 0.9999) between pump outlet flows collected either by manually adjusting the pump stroke or using the Clemson Controller (Figure 5).

The Clemson Controller closely followed the assigned target $\mathrm{N}$ rates. The result of variable-rate $\mathrm{N}$ application accuracy tests is given in Figure 6. There was an excellent correlation between the targeted and measured $\mathrm{N}$ rates with an average overall error of less than $0.5 \%$ and maximum absolute error of $2 \%$. This indicates that it is possible to match $\mathrm{N}$ rates with the spatial field variability to reduce fertilizer inputs and expenditures.

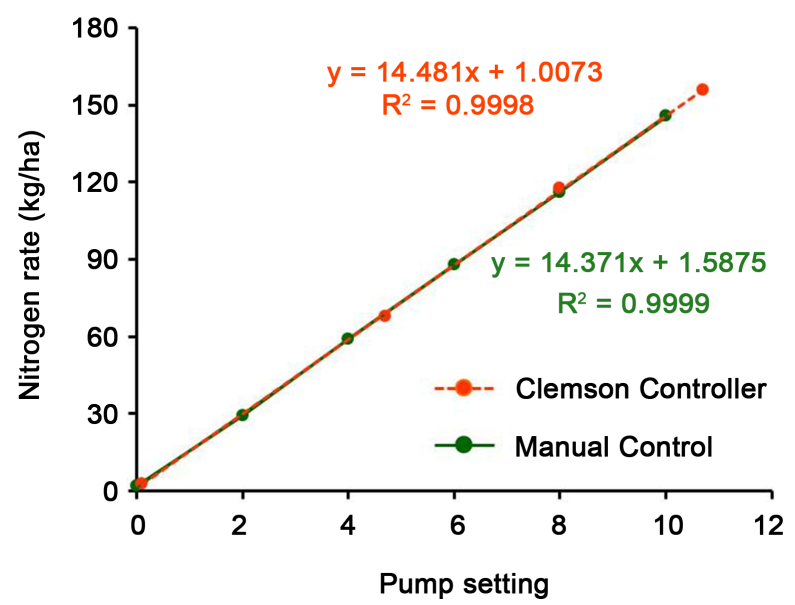

Figure 5. Correlation between pump outlet flows collected either by manually adjusting the pump stroke or using the Clemson controller. 


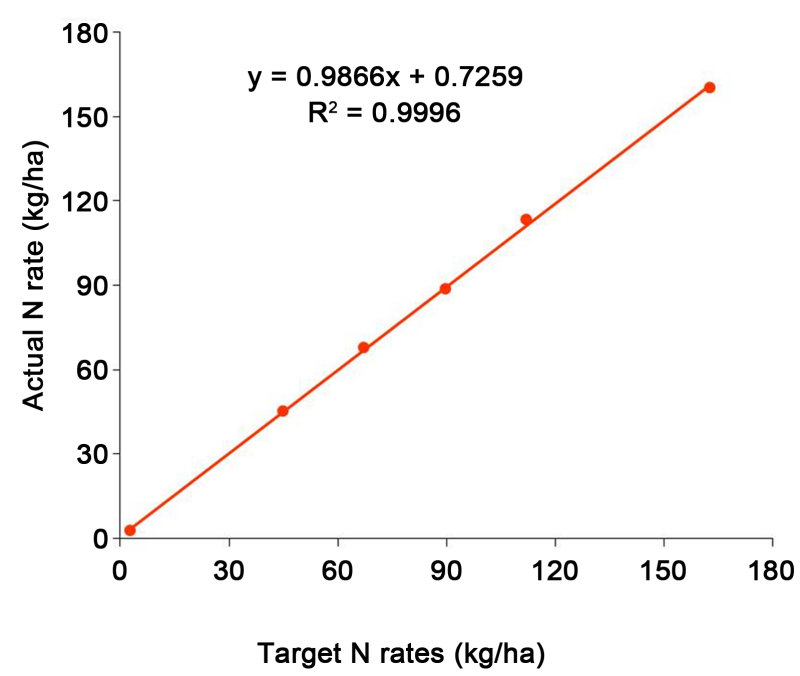

Figure 6. Correlation between targeted and measured $\mathrm{N}$ rates for the Clemson electromechanical controller.

The controller also successfully converted the GreenSeeker NDVI data into N rates, using the Clemson $\mathrm{N}$ algorithms, and controlled actuator's travel distance with similar accuracy of electric dial tests. It was also easy to enter "User Inputs" into the controller, using the keyboard on the controller box. The system also displayed the NDVI values and $\mathrm{N}$ rates on the controller's display.

\section{Discussion}

The Clemson electro-mechanical controller for adjusting pump stroke on-the-go was designed to replace the current manual stroke adjustment system on positive displacement piston pumps. This new design will enable growers to apply fertilizers where they are needed in a production field at optimum rates to increase crop yields, reduce production costs, and eliminate the negative impact of chemical on environment. The Clemson electro-mechanical system offers several advantages:

- The new device is as accurate as the current manual stroke adjustment systems (Figure 5).

- The system can be retrofitted on several existing John Blue piston pumps, using four bolts.

- Fertilizer rates can be adjusted from the tractor's cab manually, while driving through the field. This option is not available with the current manual stroke adjustment systems.

- Growers can develop a fertilizer prescription map for their production fields based on previous crop yields, soil texture maps, or soil electrical conductivity data. The prescription map then can be used to control the pump stroke on the go to apply fertilizers site-specifically, which cannot be done with the current manual systems.

- In contrast to the existing manual adjustment system, the electro-mechanical 
controller, can receive signals from several commercially available sensors (such as a pressure sensor, optical GreenSeeker sensor, or a flowmeter). For example, in the GreenSeeker sensors, the controller utilizes fertilizer calculation algorithms, previously developed for wheat, corn, and dryland or irrigated cotton, to determine the optimum rate of the fertilizer, and adjust the pump strokeon-the-go to apply right amount of fertilizer where it is needed. This option is currently not available with the manual systems.

One disadvantage of the Clemson electro-mechanical system is the requirement of a rate controller (such as Trimble, Raven, or AgLeader monitors), when using the prescription map option. This option will require uploading of the prescription map into a rate controller; however, these rate controllers are not required with other options (i.e., sensor-based or manual electric dial).

\section{Summary}

An electro-mechanical controller was developed for adjusting pump stroke on-the-go to replace the current manual stroke adjustment system on positive displacement piston pumps. The system closely followed the design specifications described in the Methodology section. This affordable system could be retrofitted on most existing John Blue piston pumps for real-time adjustment of the pump stroke. The system could be controlled using pre-described position sequences (map-based) or real-time sensor commands (such as a pressure sensor, optical GreenSeeker sensor, or a flowmeter) combined with fertilizer calculation algorithms. In addition, the system could adjust pump stroke manually from the tractor's cab using an eclectic dial. There was an excellent correlation $\left(\mathrm{R}^{2}=0.9999\right)$ between pump outlet flows collected either by manually adjusting the pump stroke or using the Clemson Controller. Also, there was a very good correlation between targeted and measured $\mathrm{N}$ rates with an average overall error of less than $0.5 \%$ and maximum absolute error of $2 \%$. Therefore, this system can be successfully used to match $\mathrm{N}$ rates with the spatial field variability to reduce fertilizer inputs and expenditures.

\section{Acknowledgements}

Technical Contribution No. 6580 of the Clemson University Experiment Station. This material is based upon work supported by NIFA/USDA, under project number SC-1700540. The authors also acknowledge the funding support of the Clemson University Research Foundation and the SC Cotton Board.

\section{Disclaimer}

Mention of a trade name does not imply endorsement of the product by Clemson University to the exclusion of others that might be available.

\section{References}

[1] Khalilian, A., Porter, W., Henderson, W., Han, Y. and Barnes, E. (2011) Sensor 
Based N Management for Cotton Production in Coastal Plain Soils. Proceedings of the Beltwide Cotton Conferences, Atlanta, 4-7 January 2011, 531-537.

[2] Manring, N.D. (1996) Displacement Control for a Variable Displacement Axial Piston Pump. Patent Number: US 5,564,905.

[3] Gollner, W. (2005) Control Device for a Proportionally Adjustable Hydraulic Pump and a Variable Displacement Pump for a Hydrostatic Drive. Patent Number: US $6,837,046$ B2.

[4] Firth, D. and Hancock, R. (1964) Swash Plate Pumps and Motors. Patent Number: US $3,117,529$.

[5] Zimmermann, D.E. (2001) Variable Displacement Hydraulic Piston Unit With electrically Operated Variable Displacement Control and Timing Control. Patent Number: US 6,176,684 B1.

[6] Du, H.L. (2013) Method and Apparatus for Controlling a Variable Displacement Hydraulic Pump. Patent Number: US 8,596,057 B2.

[7] Porter, W., Khalilian, A., Henderson, W. and Han, Y. (2010) Sensor-Based Site-Specific N Management in Cotton. Proceedings of the Beltwide Cotton Conferences, New Orleans, 4-7 January 2010, 518-523.

[8] Rogers, N.G. (2016) Sensor Based Nitrogen Management for Corn Production in Coastal Plain Soils. All Theses, Clemson University.

http://tigerprints.clemson.edu/all_theses/2579

[9] Jones, R.K. (2003) Variable-Rate Pump. Patent Number: US 6,606,935 B2.

[10] Khalilian, A., Han, Y.J., Maja, J.M., Marshall, M.W., Mirzakhani-Nafchi, A., Payero, J.O. and Anco, D.J. (2017) Development of GPS-Based Multi-Channel Controllers for Research Plot Pesticide Applicators. Journal of Agricultural Sciences, 8, 302-315. https://doi.org/10.4236/as.2017.84022

\section{Scientific Research Publishing}

Submit or recommend next manuscript to SCIRP and we will provide best service for you:

Accepting pre-submission inquiries through Email, Facebook, LinkedIn, Twitter, etc. A wide selection of journals (inclusive of 9 subjects, more than 200 journals)

Providing 24-hour high-quality service

User-friendly online submission system

Fair and swift peer-review system

Efficient typesetting and proofreading procedure

Display of the result of downloads and visits, as well as the number of cited articles

Maximum dissemination of your research work

Submit your manuscript at: http://papersubmission.scirp.org/

Or contact as@scirp.org 